\title{
AGITATION WITHIN MK-42 INSERT CAUSED BY AIR SPARGE (U)
}

by

\author{
C. J. Ramsey
}

Westinghouse Savannah River Company

Savannah River Laboratory

Aiken, South Carolina 29808

\section{DISCLAIMER}

\section{A DP Report due}

July 12,1991

\begin{abstract}
This report was prepared as an account of work sponsored by an agency of the United States Government. Neither the United States Government nor any agency thereof, nor any of their employees, makes any warranty, express or implied, or assumes any legal liability or responsibility for the accuracy, completeness, or usefulness of any information, apparatus, product, or process disclosed, or represents that its use would not infringe privately owned rights. Reference herein to any specific commercial product, process, or service by trade name, trademark, manufacturer, or otherwise does not necessarily constitute or imply its endorsement, recommendation, or favoring by the United States Government or any agency thereof. The views and opinions of authors expressed herein do not necessarily state or reflect those of the United States Government or any agency thereof.
\end{abstract}

This paper was prepared in connection with work done under Contract No. DE-AC09-89SR18035 with the U.S. Department of Energy. By acceptance of this paper, the publisher and/or recipient acknowledges the U.S. Government's right to retain a nonexclusive, royalty-free license in and to any copyright covering this paper, along with the right to reproduce and to authorize others to reproduce all or part of the copyrighted paper. 
WSRC-TR-91-159

12 March, 1991

$\begin{array}{ll}\text { TO: } & \text { D. F. Chostner, 221-F } \\ \text { FROM: } & \text { C. J. Ramsey, 305-A Cl/ }\end{array}$
CC: J.G. McKibbin, 707-F

J.E. Dickenson, 707-F

G.E. Barrow, 221-F

R.H. Spires, 221-F

R.C. Marozas, 707-F

A.P. Gouge, 221-H

S.E. Albrecht, 221-14F

T.A. Reilly, 707-F

A.R. Biebesheimer, 704-F

J.E. Black, 773-A

A.L. Blancett, 773-A

\section{AGITATION WITHIN MK-42 INSERT CAUSED BY AIR SPARGE (U)}

\section{INTRODUCTION}

Dissolution of Rocky Flats Pu alloys and Pu metal using a "nested insert" configuration (One Well Insert (S-3352) inside the Mk-42 Insert) will require a Nuclear Safety Study, a major assumption of which will be that the annular dissolver is well-mixed. The "well-mixed" assumption was theoretically and experimentally supported for alloy dissolution using the Three Well Insert ${ }^{1,2}$, but the present situation differs significantly. In the former case, the insert was directly exposed to the agitation induced by air sparging; in the case under consideration, the One Well Insert would be shielded by the Mk-42 Insert. In an effort to determine if the "nested insert" approach should be pursued, the past studies and technical literature have been surveyed and an attempt made to predict the extent of mixing and bulk circulation for a "nested insert" configuration in the presence of air sparging.

\section{SUMMARY}

The main conclusion of this survey is that the dissolver vessel is well-mixed and that flow within the Mk-42 Insert should be adequate to prevent a concentration buildup around the One Well Insert. Experimental work is currently underway to support this conclusion and in my opinion work should proceed on the fabrication of the One-Well Inserts. A secondary conclusion is that spargers in 6.1D and 6.4D provide a uniform distribution of air over the range of operating flowrates. This determination was required to address the primary question.

\section{ANALYSIS}

The following parameters, based on operating conditions, were used in the analysis: a) air flowrate ranging from 0.007 to $0.024 \mathrm{~m}^{3} / \mathrm{s}$ (900 to $\left.3000 \mathrm{SCFH}\right)$ at a delivery pressure of 480 to $520 \mathrm{kPa}$ (70 to $75 \mathrm{psig})$, b) solution temperature ranging from 45 to $55^{\circ} \mathrm{C}$ (Pu metal) and 80 to $85^{\circ} \mathrm{C}$ (alloys), c) liquid depth constant at approximately $1.8 \mathrm{~m}$ (6 feet), and d) solution density

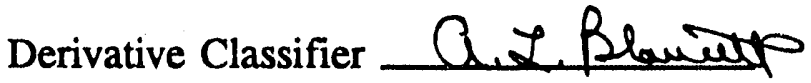


and viscosity approximately the same as for water. Geometrical details of the vessel and sparge assemblies were also provided. The first question addressed was: Does the sparger produce a uniformly distributed flow, especially at the lowest flowrate? The analysis indicates that it does. I was not able to locate an original design basis stating this fact, but the analysis presented here (see attached sheets) could serve that purpose. Remote visual inspection of the free surface in the dissolver has been proposed to verify proper sparger distribution.

The second question - Is air-sparged mixing "acceptable" as related to a Nuclear Safety Study? is currently being resolved. The gas-liquid mixing literature which I have been able to locate is generally limited to small bubble columns or air-lift reactors, vessels which are typically free of major obstructions (e.g. dissolver inserts, steam coils) within the working volume. Given the fact that dissolver inserts are not intended or designed to serve as flow obstructions, the effects were assumed to be negligible. Experimental work will verify this assumption.

Two indicators of mixing performance are circulation time and mixing time. Circulation time is defined as the average time required for a particle or dye tracer to traverse the major dimensions of the vessel; it serves as a good indicator of large scale or bulk dispersion. Mixing time is defined as the time required for a dye or chemical tracer to reach some predetermined level of uniform concentration. Mixing time is usually a strong function of circulation time.

Two independent correlations were used to obtain rough estimates of mixing time in an unobstructed vessel. One, based on work performed by Lehrer ${ }^{3}$, relates the volume of the vessel contents to the volume of input air needed to produce uniform mixing (the necessary endpoint for a mixing time calculation). Mixing time can be inferred from from volumetric flowrate. The air/liquid volume ratio was found to be approximately $1: 2$. The second correlation is reported by Tatterson ${ }^{4}$. It derives from investigations by Smith et al. ${ }^{5}$ into the mixing of large ponds using bubble columns, and relates gas flowrate to liquid flowrate at the free surface. Bulk circulation time can be inferred from the major dimensions of the vessel, and used to estimate mixing time based on an approximation from previous mixing research, i.e. mixing occurs in five volume turn-overs 4 .

Values of bulk circulation and mixing time (in seconds) are reported in the table below. The two times listed are for minimum and maximum air flowrates, respectively. All calculations and related notes are included in the attachment.

\begin{tabular}{|c|c|c|c|}
\hline Reference & Basis & $\begin{array}{c}\text { Circulation Time } \\
(\mathrm{sec})\end{array}$ & $\begin{array}{c}\text { Mixing Time } \\
(\mathrm{sec})\end{array}$ \\
\hline 3 & volume ratio & 130,40 & $670,200 *$ \\
\hline 4 & flowrates & $110,80^{*}$ & 570,380 \\
\hline
\end{tabular}

* Values calculated directly from given relation. 
Based on the circulation times and the assumption that gross flow patterns are primarily vertical, fluid velocities are estimated to range from 3 to $9 \mathrm{~cm} / \mathrm{s}(0.1$ to $0.3 \mathrm{ft} / \mathrm{s})$ for the first set of values and 3 to $5 \mathrm{~cm} / \mathrm{s}(0.1$ to $0.2 \mathrm{ft} / \mathrm{s})$ for the other. These velocities indicate turbulent conditions in all cases (see attached calculations).

The presence of strong vertical fluid velocities suggests that a recirculation pattern would be established within the dissolver, with downdrafts set up in the Mk-42 Insert. This would prevent the quiescence necessary for a concentration buildup around the One Well Insert. The existence of a turbulent flowfield further weakens the probability of a liquid volume within the Mk-42 Insert remaining isolated and quiescent for any appreciable length of time; turbulent diffusion is orders of magnitude greater than molecular diffusion. However, it is possible to conceive of a scenario in which the fluid inside the $\mathrm{Mk}-42$ Insert is dynamically isolated from the fluid in the bulk of the dissolver, and this would lead to dead zones within the Mk-42. If this were true, the vessel could not be considered well-mixed.

Experiments are currently underway to determine the feasibility of this scenario. Mixing studies will also be done to verify the correlations used in this analysis. The projected closing date for the experimental work is May 31, 1991. A final report will be submitted based on the experimental results and the indication of mixing within the "nested insert" configuration.

\section{REFERENCES}

1) DPST-84-472, "Air Sparge Mixing Studies in the Annular Dissolvers," F.R. Graham, April 30, 1984.

2) DPST-85-494, "Mixing Studies in 6.4D Dissolver Mockup," A.C. Thompson and F.R. Graham, May 15, 1985.

3) R.H. Perry and D.W. Green, ed., Perry's Chemical Engineers' Handbook, 6th Edition, McGraw Hill, Inc., 1984, p.18-61 (based on L.H. Lehrer, "Gas Agitation of Liquids," I\&EC Process Design and Developm nt, Vol. 7, No. 2, April, 1968.).

4) G.B. Tatterson, Fluid Mixing and Gas Dispersion in Agitated Tanks, McGraw-Hill, Inc., 1991, p. 307.

5) J.M. Smith et al., Proc. 6th Eur. Conf. on Mixing, BHRA Fluid Engineering, Cranfield, England, C2, 1982, pp. 71-79.

\section{ATTACHMENTS}

- Sparger Distribution Analysis

- Circulation and Mixing Time Calculations 


\section{Sparger Distribution Analysis}

In previous studies of the mixing induced by air sparging in the annular dissolvers, it was assumed that air was discharged into the vessel uniformly around the circumference of the sparger. F. R. Graham raised the issue of uniform distribution in DPST-85-494, recommending that "further studies... be conducted to determine the minimum sparge rate to ensure flow to all of the holes in the sparge ring." An analysis was undertaken to determine if uniform air distribution could be assumed for the spargers in the annular dissolvers.

The analysis is based on a technical note by K. S. Knaebel entitled "Simplified Sparger Design" (Chem Engr; March 9, 1981; p.116). A simple relation between the orifice diameter (d), the sparge ring diameter $(D)$, and the number of orifices $(N)$ is given as:

$$
d \leq 0.7 \frac{D}{\sqrt{N}}
$$

This equation is valid when: 1) the flow within the sparge ring is turbulent, 2) the length to diameter ratio of the sparge ring is less than 150, and 3) the number of orifices $(N)$ is large (i.e. $N>1$ ). A sparge ring can be represented as a piping network with two branches, each branch of length equal to half of the ring circumference with half the orifices and half of the total air flow. It can be demonstrated that all of the conditions listed above apply to both sparger rings in the 6.1D, as well as the single sparge ring in the 6.4D.

The sparge ring diameter $(D)$ and number of orifices $(N)$ are known (in $6.1 D$, for the outer sparge ring, $D^{\dagger}=2.7^{\prime \prime}$ and $N=64$; for the inner ring $D^{+}=2.1^{\prime \prime}$ and $N=40$; in $6.4 \mathrm{D}, D=$ $1.9^{\prime \prime}$ and $\left.N=161\right)$. Utilizing the equation given above, the diameters of each orifice $(d)$ for the respective sparge rings can be determined.

For the spargers in the $6.1 \mathrm{D}, d$ is approximately $0.33^{\mathrm{N}}$. In the technical note, a recommendation is made to reduce this value by half, leading to an orifice diameter of approximately $0.17^{n}$. The actual orifice diameter is $0.125^{\prime \prime}$, the next smallest common drill size. My conclusion is that similar design calculations were performed when these spargers were designed, and that maldistribution of the flow is less than $5 \%$. In other words, for purposes of analyzing the sparger induced mixing in the annular dissolvers, it can be assumed that each orifice discharges an equal amount of air.

For the sparge ring in the $6.4 \mathrm{D}$, the design orifice diameter $(d)$ is $0.15^{\prime \prime}$. The actual orifice size is $0.125^{\prime \prime}$, which is not as small as the recommended diameter ( $0.15^{n}$ divided by two) but still less than the calculated value. This sparger can also be assumed to be a uniform distributor.

+ Since this sparge ring has a rectangular cross-section, the hydraulic diameter is used.

* Based on the two-branch representation discussed above; i.e. $N$ is divided by two. 
- from Perry et al. ${ }^{3}$ :

The volume of gas required to obtain "thorough blending of inviscid liquids of equal viscosities" is about one-half of the vessel volume, this according to air-sparged mixing studies conducted by Lehrer (as reported by Perry et al.). The annular dissolver has an O.D. of 122" (3.1 m), an I.D. of $68^{\mathrm{n}}(1.7 \mathrm{~m})$, and the liquid depth equals 6 feet $(1.83 \mathrm{~m})$. This leads to a total liquid volume of roughly $9.5 \mathrm{~m}^{3}$ and an air volume of $4.75 \mathrm{~m}^{3}$ to achieve mixing. The total gas flowrate to the vessel varies from 15 to 50 SCFM $\left(7.08(10)^{-3}\right.$ to $\left.2.36(10)^{-2} \mathrm{~m}^{3} / \mathrm{s}\right)$. Mixing time $(\theta)$ can be inferred from gas flowrate. For the maximum and minimum air flowrates given above, this leads to:

$$
\theta_{\min } \simeq 201 \mathrm{sec} \quad \theta_{\max } \simeq 671 \mathrm{sec}
$$

Note that the minimum time is associated with the maximum flowrate, and vice versa. One volume turn-over (i.e. one circulation time $(T)$ ) is assumed to equal one-fifth of the mixing time $e^{4}$. This leads to the following circulation times:

$$
\mathrm{T}_{\min }=40 \mathrm{sec} \quad \mathrm{T}_{\max } \simeq 134 \mathrm{sec}
$$

- from Tatterson ${ }^{4}$ (based on Smith et al. ${ }^{5}$ ):

$$
\frac{Q_{L}^{3}}{Q g H^{5}}-4(10)^{-4}
$$

where $Q_{L} \equiv$ liquid flowrate at free surface

$Q \equiv$ gas flowrate

$H \equiv$ liquid depth

This equation derives from work involving the agitation of large ponds with unconstrained bubble columns. Assuming that each orifice discharges an unconstrained bubble column, the equation given above yields:

$$
\mathrm{Q}_{\mathrm{LEx}}=0.0828 \mathrm{~m}^{3} / \mathrm{s} \quad \mathrm{Q}_{\max }=0.1237 \mathrm{~m}^{3} / \mathrm{s}
$$

where the minimum and maximum liquid flowrates are based on the range of gas flowrate. As indicated above, the vessel volume is approximately $9.5 \mathrm{~m}^{3}$, leading to the following circulation times:

$$
\mathrm{T}_{\min } \simeq 77 \mathrm{sec} \quad \mathrm{T}_{\max } \simeq 115 \mathrm{sec}
$$

Based on the assumption that mixing occurs after five volume turn-overs, mixing time $(\theta)$ can be estimated:

$$
\theta_{\text {min }} \simeq 384 \mathrm{sec} \quad \theta_{\max } \simeq 574 \mathrm{sec}
$$



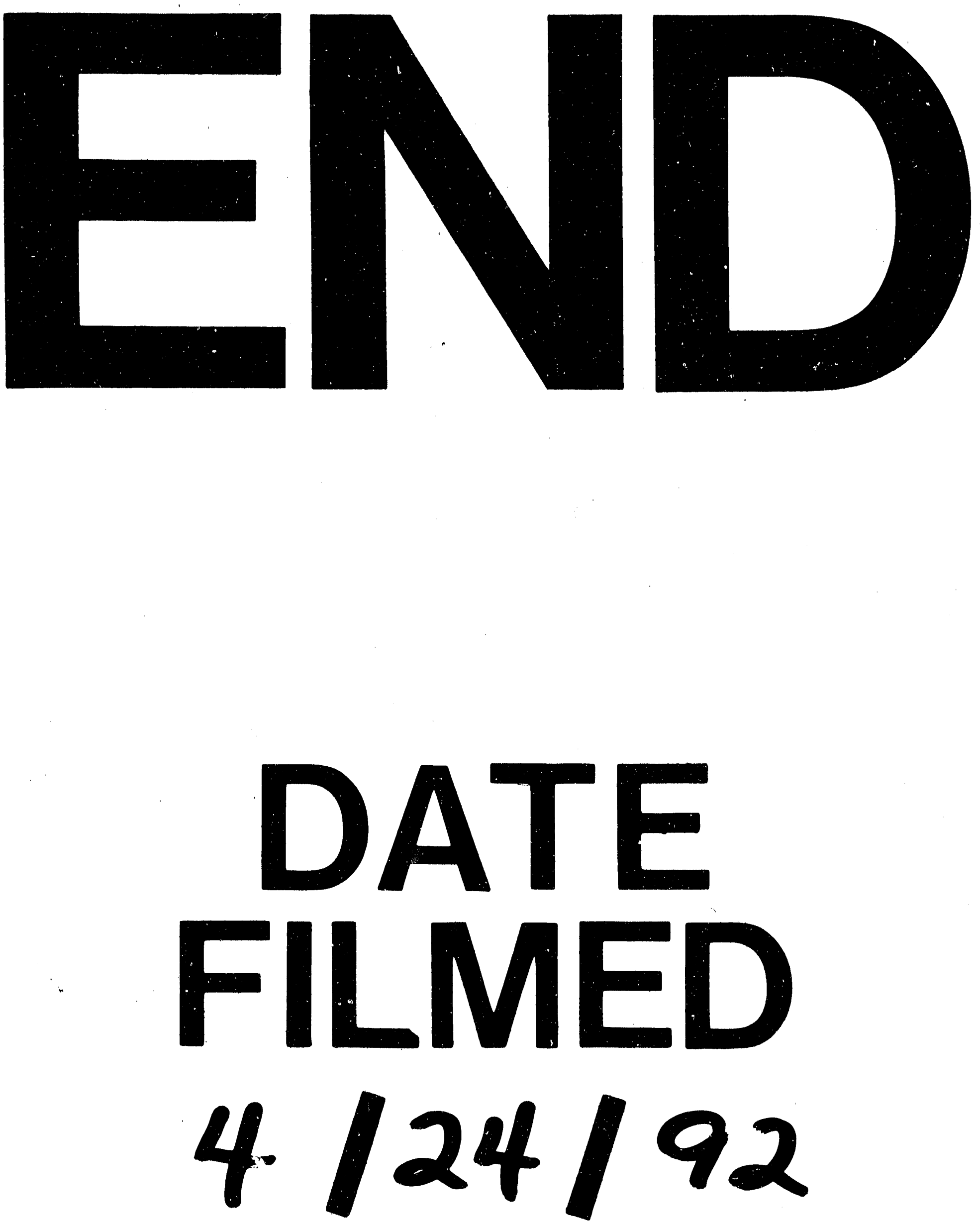
